\title{
A Rare Case of Familial Multiple Sclerosis
}

Rima $\mathbf{R}^{*}$

Department of Neurology, Army hospital Research and Referal, New Delhi, Delhi P.O. Box: 110010, India

\begin{abstract}
Multiple sclerosis (MS) is a chronic disease confined to the central nervous system (CNS). While the cause is not clear, proposed causes for this include genetics and environmental factors such as infections. Although most MS cases occur sporadically, a considerable proportion, as many as 20 percent, of the patients are related by family. Whereas familial aggregation of MS is a well-known phenomenon in high prevalence areas, it is considered very rare in Asia, a low prevalence area. We are describing a case of two sisters presenting with Multiple sclerosis, one with RRMS and other with SPMS.
\end{abstract}

Keywords: Multiple sclerosis; Chronic disease; Central nervous system; Genetics

\section{Introduction}

Multiple sclerosis (MS) is a chronic disease confined to the central nervous system (CNS). Its pathological hallmarks are neuroinflammation, de- and remyelination, neurodegeneration and astrogliosis. This neuroinflammation disrupts the neurological circuits, resulting in a varied signs and symptoms including physical, cognitive and psychiatric problems. MS occurs either in relapsing form or in progressive form.

The underlying mechanism is either destruction of neurons by the immune system or failure of the myelin-producing cells. The proposed mechanism for MS includes genetics and certain environmental factors. MS is diagnosed occording to Mcdonald criterion 2010, which is based on signs, symptoms and neuroimaging. Most of the MS cases occur sporadically, but about 20 percent, of them can be familial $[1,2]$. The risk of familial MS had been reported to be increased from 12- to 38 -fold in siblings, six- to 25-fold in children of MS patients [3] and from seven- to 26-fold in parents [4-9]. Familial aggregation of MS is commonly seen in highly prevalent areas [10] but is very rare in Asia, a area having a low prevalence [11]. However, the few studies that have addressed the familial risk of MS in low prevalence areas have been seriously limited by modest numbers of MS patients $\mathrm{P}$ [12].

\section{Case Report}

A 34 year old lady became symptomatic in 2008 with acute onset of paresthesias in bilateral lower limbs, with spontaneous recovery in one month. Thereafter she had multiple similar episodes over next 2 years. In feburary 2010 she had a similar episode of paresthesisas in bilateral upper and lower limb which remained static for further two years and thereafter she had partial recovery of symptoms. In November 2010 she had insidious onset progressive gait and appendicular ataxia leading to difficulties in activitis of daily living. She had one missed abortion and had one normal delivery two years back. She is a non smoker and does not use illicit or reacreational drugs.

Neurologically she had grade 2 spasticity in both lower limbs, all DTJ, were pathologically brisk, both planters were extensors, vibration and propioception loss in both LL. She had clumsy finger nose, past pointing and knee shin test. She had intentional tremors in all limbs and ataxic gait. Neuroimaging was suggestive of multiple discrete T2W and flair hyperintesities in pericallossal, justacortical, periventricular regions with no Gad enhanced lesions. Black holes were also seen in T1W images. CSF for oligoclonal bands was positive. Her autoimune profile was negative.
Her elder sister presented at a age of 33 years with paresthesia in both hands and gait ataxia. Neuroimaging was suggesting of multiple discrete areas of signal attenuation in periventricular region, subcortical white matter, brainstem and spinal cord suggesting of demyelinating plaques. Diagnosed a case RRMS, started on prophylaxis initially on interferon. She had multiple relapses while on interferon thus subsequently started on fingolimod with no recurrences for last 2 years.

\section{Discussion}

Multiple sclerosis (MS) is an inflammatory autoimmune disorder of the central nervous system characterized by recurring neurologic symptoms MS typically presents in early adulthood and is considered the most common cause of neurologic disability in young adults [1]. In the contemporary history of multiple sclerosis (MS), the familial recurrence rate is estimated at about $15 \%$ and is variable in geographic locations or absent in some ethnic groups $[13,14]$. The earliest collection and report of familial cases were by Curtius in 1933 [15]. Pratt et al. in 1951 described the first incidence rate of $6.5 \%$ in a collection of 310 cases and proposed the concept of polygenetic inheritance [16]. Jersild et al. [17] was the first to report an association between the disease and certain alleles of the HLA complex thus providing evidence in support of the genetic nature of MS. Further the genome-wide association studies confirmed about 59 genetic variants associated with MS [18].

Our patient had disease onset at 28 yrs and her elder sister had MS at 33 yrs of age. It has been seen in some studies, that the onset of familial MS is in younger age groups than non-familial MS but this was not in our case. Familial MS has been found in younger ages than nonfamilial MS in other studies. A study on familial MS in Spain concluded that it affects individuals about 8 years earlier than non-familial MS (22 vs. 30 years old). Another large study based on PPMS patients found that familial MS starts sooner, than non familial MS with a median age of 37.6 vs. 42.7 years [19].

Some studies delineated that familial MS is more common among

*Corresponding author: Rumpaul Rima, Army hospital Research and Referal, New Delhi, Delhi P.O. Box: 110010, India, Tel: 01145151695; E-mail: rumpaulrima@gmail.com

Received September 29, 2015; Accepted October 17, 2015; Published October 20, 2015

Citation: Rima R (2015) A Rare Case of Familial Multiple Sclerosis. J Neurol Disord S1: 006. doi:10.4172/2329-6895.S1-006

Copyright: (c) 2015 Rima R. This is an open-access article distributed under the terms of the Creative Commons Attribution License, which permits unrestricted use, distribution, and reproduction in any medium, provided the original author and source are credited. 
first and third degree relatives with MS. In other studies frequency of MS in first and second degree relatives of MS patients has been estimated $22.8 \%$. A meta-analysis found that relative risk for MS is $9.2,3.4$ and 2.9 in first, second and third degree relatives of MS patients, respectively [20]. Our patients are product of nonconsangunous marriage and are first degree relatives.

Familial MS was more common among siblings, with sistersister relationship having the highest rate. The lowest relation was among father-son and mother son. Mantomoli showed that the risk of MS among siblings is $4.7 \%$ which is 31 times higher than general population [21] Ebers [22] showed that the probability of having MS is $3.5 \%$ among siblings. Higher rates among sisters can be attributed to higher prevalence of disease among females. This may be also due to similar genes, similar environment or both. However, a cohort study in Denmark showed relatively similar relative risk for familial MS in parents, offspring and non-twin siblings [23].

Although MS is higher in women in the general population, among patients with familial MS, men had a significantly higher ratio than women, with a ratio of 2.61. The study in Khouzestan province, Iran also found that positive family history of MS was significantly higher among men [24] Also, the national cohort performed in Denmark, found that the relative risk of familial MS was lower in females and relatives of male MS patients had higher relative risk compared with female patients. A large Danish study of 13,286 people with MS showed that amongst identical twins the risk was $24 \%$, and for non-identical twins the risk was $3 \%$. A first degree relative such as the son of a mother with MS, has 20-40 times the risk of getting the disease than someone without such a relative [25].

Our patient is a product of nonconsanginous marriage, are sisters and the younger sibling had severer disease than the elder sister. Younger had SPMS and the elder one had RRMS. Symptomology is different in these two individuals. In ASIA the incidence of familial MS is lower.

Concordant siblings tend to share age of symptoms onset rather than year of onset, suggesting that inherited factors distinct from a common environmental exposure influence susceptibility. Studies of half-siblings and adoptees support the concept that genetic, and not environmental factors, are primarily responsible for familial aggregation $[20,25]$ In this case both were brought up in India but elder sibling had migrated to Canada 8 years before the onset of the disease.

A strong genetic component in MS pathogenesis is indicated foremost by the relative high-recurrence risk in family members of affected individuals and frequent occurrence in some ethnic populations (particularly those of northern European origin) compared with others (African and Asian groups), irrespective of geographic location [26-28].

\section{References}

1. Kahana E (2000) Epidemiologic studies of multiple sclerosis: a review. Biomed Pharmacother 54: 100-102.

2. Carton H, Vlietinck R, Debruyne J, De Keyser J, D'Hooghe MB, et al. (1997) Risks of multiple sclerosis in relatives of patients in Flanders, Belgium. J Neurol Neurosurg Psychiatry 62: 329-333.

3. Grasso MG, Frontali M, Bernardi S, Pantano P, Fieschi C (1989) Multifactorial inheritance and recurrence risks of multiple sclerosis in Italian patients. Neuroepidemiology 8: 300-307.

4. Montomoli C, Prokopenko I, Caria A, Ferrai R, Mander A, et al. (2002) Multiple sclerosis recurrence risk for siblings in an isolated population of Central Sardinia, Italy. Genet Epidemiol 22: 265-271.

5. Robertson NP, Fraser M, Deans J, Clayton D, Walker N, et al. (1996) Ageadjusted recurrence risks for relatives of patients with multiple sclerosis. Brain 119: $449-455$.
6. Sadovnick AD, Baird PA (1988) The familial nature of multiple sclerosis: age-corrected empiric recurrence risks for children and siblings of patients. Neurology 38: 990-991.

7. Sadovnick AD, Baird PA, Ward RH (1988) Multiple sclerosis: updated risks for relatives. Am J Med Genet 29: 533-541.

8. Dyment DA, Ebers GC, Sadovnick AD (2004) Genetics of multiple sclerosis. Lancet Neurol 3: 104-110.

9. Marrosu MG, Lai M, Cocco E, Loi V, Spinicci G, et al. (2002) Genetic factors and the founder effect explain familial MS in Sardinia. Neurology 58: 283-288.

10. Prokopenko I, Montomoli C, Ferrai R, Musu L, Piras ML, et al. (2003) Risk for relatives of patients with multiple sclerosis in central Sardinia, Italy. Neuroepidemiology 22: 290-296.

11. Tan CT (1988) Multiple sclerosis in Malaysia. Arch Neurol 45: 624-627.

12. Bansil S, Singhal BS, Ahuja GK, Ladiwala U, Behari M, et al. (1996) Comparison between multiple sclerosis in India and the United States: a case-control study. Neurology 46: 385-387.

13. A. Compston and $H$. Werkele, "The genetics of multiple sclerosis," in Mcalpine's Multiple Sclerosis, pp. 126-136, Churchill Livingston, London, UK, 4th edition, 2005.

14. J. Flores, S. Gonzalez, X. Morales, P. Yescas, A. Ochoa, and T. Corona, "Absence of multiple sclerosis and demyelinating diseases among Lacandonians, a pure Amerindian group in Mexico," Multiple Sclerosis International, vol. 2012, Article ID 292631, 4 pages, 2012.

15. Curtius F (1933) Multiple Sklerose Und Erbanlage, Thieme, Leipzig, Germany.

16. Pratt RT, Compston ND, mcalpine D (1951) The familial incidence of disseminated sclerosis and its significance. Brain 74: 191-232.

17. Jersild C, Svejgaard A, Fog T (1972) HL-A antigens and multiple sclerosis Lancet 1: 1240-1241.

18. International Multiple Sclerosis Genetics Consortium; Wellcome Trust Case Control Consortium 2, Sawcer S, Hellenthal G, Pirinen M, Spencer CC, et al (2011) Genetic risk and a primary role for cell-mediated immune mechanisms in multiple sclerosis. Nature 476: 214-219.

19. Amela-Peris R, Aladro Y, Conde-Sendín MA, Alemany-Rodríguez MJ, MuñozFernández C, et al. (2004) [Familial multiple sclerosis in Canary Islands]. Rev Neurol 39: 911-914.

20. Ebers GC, Sadovnick AD, Risch NJ (1995) A genetic basis for familia aggregation in multiple sclerosis. Canadian Collaborative Study Group. Nature 377: 150-151.

21. Montomoli C, Allemani C, Solinas G, Motta G, Bernardinelli L, et al. (2002) An ecologic study of geographical variation in multiple sclerosis risk in central Sardinia, Italy. Neuroepidemiology 21: 187-193.

22. Ebers GC, Paty DW. Studies in familial multiple sclerosis in North Khouzestan Dezfoul; Dezful Azad University of Medical Sciences, 1998. (Dissertation)

23. Koch-Henriksen N, Rasmussen S, Stenager E, Madsen M (2001) The Danish Multiple Sclerosis Registry. History, data collection and validity. Dan Med Bull 48: 91-94.

24. Maliars'ka NV (1997) [Familial forms of multiple sclerosis]. Lik Sprava : 134-135

25. Sadovnick AD, Ebers GC, Dyment DA, Risch NJ (1996) Evidence for genetic basis of multiple sclerosis. The Canadian Collaborative Study Group. Lancet 347: $1728-1730$.

26. Ebers GC, Sadovnick AD (1994) The role of genetic factors in multiple sclerosis susceptibility. J Neuroimmunol 54: 1-17.

27. Oksenberg JR, Seboun E, Hauser SL (1996) Genetics of demyelinating diseases. Brain Pathol 6: 289-302.?11.

28. Oksenberg JR, Barcellos LF (2000) The complex genetic aetiology of multiple sclerosis. J Neurovirol 6 Suppl 2: S10-14.

This article was originally published in a special issue, Management of Neurosurgical Complications handled by Editor(s). Dr. Athanasios K. Petridis, Department of Neurosurgery, University of Schleswig Holstein, Germany 